doi:10.4149/neo_2013_003

\title{
Prognostic analysis of patients with operable gastric cancer and tolerability to adjuvant radiochemotherapy
}

\author{
M. KUCUKONER ${ }^{1, \star}$, E. ARPACI ${ }^{2}$, A. ISIKDOGAN ${ }^{1}$, M. BILICI $^{3}$, D. UNCU ${ }^{4}$, B. CETIN ${ }^{5}$, F. DANE ${ }^{6}$, M. INANC ${ }^{7}$, A. S. EKINCI ${ }^{2}$, A. INAL $^{1}$, K. CAYIR ${ }^{3}$,

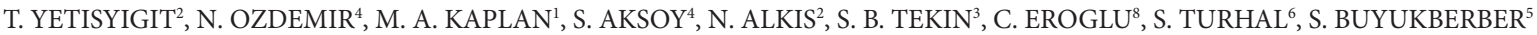

${ }^{1}$ Dicle University, Medical Oncology Department, Diyarbakir, Turkey; ${ }^{2}$ Ankara Oncology Hospital, Ankara, Turkey; ${ }^{3}$ Erzurum Atatürk University, Medical Oncology Department, Erzurum, Turkey; ${ }^{4}$ Ankara Numune Hospital, Medical Oncology Department, Ankara, Turkey; ${ }^{5}$ Gazi University, Medical Oncology Department, Ankara, Turkey; ${ }^{6}$ Marmara University, Medical Oncology Department, Istanbul, Turkey; ${ }^{7}$ Erciyes University, Medical Oncology Department, Kayseri, Turkey; ${ }^{8}$ Erciyes University, Radiation Oncology Department, Kayseri, Turkey

*Correspondence: drmehmetonko@hotmail.com

Received February 2, 2012 / Accepted June 6, 2012

\begin{abstract}
The aim of this study is to evaluate the tolerability and toxicity of adjuvant chemoradiotherapy (CRT) and to analyze the prognosis in patients with operable gastric cancer.

The retrospective analysis included 723 patients with operable gastric cancer; stage IB-IV (M0), received adjuvant CRT from 8 Medical Centers in Turkey between 2003 and 2010. The patients' age, sex, tumor localization, Lauren classification, grade and stage of the disease, type of dissection, the toxicity and tolerability status and survival rate were analyzed. All patients were divided into two groups as tolerable group to adjuvant CRT and intolerable group to adjuvant CRT .

Among the patient, $73.9 \%$ had stage III-IVM0 disease; $61.0 \%$ had the intestinal type of gastric cancer, $51.1 \%$ had the distal type, and $61.4 \%$ had undergone D2 dissections. The number of patients who completed the entire course of the adjuvant CRT was 545 (75.4\%).

The median follow-up period was 20.8 months (range: 1.5-107 months). Overall Survival (OS) rates were $80 \%$ and $52 \%$, while the relapse free survival (RFS) rates were $75 \%$ and $48 \%$ at 1 and 3 years, respectively.

In the univariate analysis of the groups based on the the age defined as $<65$ or $\geq 65$ ( $p=0.16 / p=0.003$ ), Lauren classification $(\mathrm{p}=0.004 / \mathrm{p}<0.001)$, localization of tumor $(\mathrm{p}=0.02 / \mathrm{p}=0.04)$, tumor grade $(\mathrm{p}=0.06 / \mathrm{p}=0.003)$, disease stage $(\mathrm{p}<0.001 /$ $\mathrm{p}<0.001$ ), type of dissection ( $\mathrm{p}=0.445 / \mathrm{p}=0.043)$, presence or absence of toxicity $(\mathrm{p}=0.062 / \mathrm{p}=0.077)$ and tolerability of the therapy ( $\mathrm{p}=0.002 / \mathrm{p}=0.001$ ). In the cox regression analysis, tumor stage (Hazard Ratio (HR): 0.332; 95\% confidence interval (CI): 0.195-0.566; $\mathrm{p}<0.001$ ), and tolerability (HR: 0.516; $95 \%$ CI: $0.305-0.872 ; \mathrm{p}=0.014$ ), were found to be related with the OS. Tumor stage (HR: 0.318; 95\% CI: 0.190-0.533; $\mathrm{p}=<0.001$ ) and tolerability (HR: 0.604; 95\% CI: 0.367-0.995; $\mathrm{p}=0.048$ ) were observed to be statistically significant in terms of the RFS.

We have observed that whether a patient can or cannot tolerate adjuvant CRT due to its toxicity is an independent prognostic factor besides the known prognostic factors like tumor stage and Lauren classification. We are of the opinion that the treatment of patients who cannot tolerate adjuvant CRT should be replaced with less toxic adjuvant therapies.
\end{abstract}

Key words: gastric cancer, prognosis, tolerability

Gastric cancer is the fourth most common type of cancer and the second most common cause of cancer-related mortality around the world [1]. As a Eurasian country, the incidence of gastric cancer in Turkey is somewhere between the higher incidence observed in the Eastern world and lower incidence rates in the Western world [2]. In our country, gastric cancer is the fourth most common type of cancer and the third most common cause of cancer-related mortality [3].

The prognosis of gastric cancer continues to be poor, with a 5 -year survival rate of approximately $20 \%$ except for a few countries (e.g. $40 \%-60 \%$ in Japan) $[4,5]$. This difference between the east and the west is mainly related with the early diagnosis rates resulting from the screening programs [6]. High 
recurrence rates (40\%-80\%) subsequent to the surgery are the major problem and are often the ultimate cause of death [7].

The treatment for gastric cancer is the surgical resection of the primary tumor and the regional lymph nodes. While total gastrectomy is necessary for the lesions located in the proximal stomach, a subtotal gastrectomy may be adequate for distal lesions. The extent of the lymph node dissection (D2 or D3) to be applied in gastric cancer is still controversial. Adjuvant therapy (chemotherapy and/or radiotherapy) to reduce recurrences still warrants further evaluation in high-risk gastric cancer patients.

The stage and depth of the tumor invasion, lymph node involvement, tumor involvement in the resection line (i.e. R0, R1), primary tumor site, and the Lauren classification are the most significant prognostic factors [8,9]. Lauren described the two histological types of gastric cancer as the intestinal and the diffuse types [10]. Although the intestinal type is more common in older people and in males, the diffuse type occurs more frequently in women and in younger patients [8]. In contrast to the increasing incidence of proximal tumors in the West, distal tumors continue to predominate in Japan [11]. The tumor site has been shown to be an independent prognostic factor in gastric carcinoma, with proximal carcinomas having a poorer prognosis than distal cancers [12].

The low tolerability and high toxicity of the adjuvant CRT in older patients and in patients with lower performance scores are already well-known. One reason for the low tolerance to the adjuvant treatmant in older patients is associated with the reduction in the functional reserve of multiple organ systems (Urinary, Cardiovascular, Gastrointestinal e.g.) [13]. According to our observations, patients who cannot tolerate the post-operative adjuvant treatment have a poorer prognosis and survival rates are lower in the patients who do not complete the treatment.

The aim of this study is to evaluate the tolerability and toxicity of adjuvant CRT and analyze the prognosis in patients with operable gastric cancer.

\section{Patients and methods}

Patients. For the purposes of this study, the medical records of patients treated at eight Medical Centers in Turkey between 2003 and 2010 were retrospectively evaluated. Patients were selected from different regions of the country in order to reflect the entire Turkish population. A total of 723 patients with operable gastric cancer were included in the study.

The inclusion criteria were a histologically confirmed adenocarcinoma of the stomach or the gastroesophageal junction, and a performance status equal to or lower than 2 according to the Southwest Oncology Group criteria. All patients were over 18 years of age and had undergone a complete resection of the tumor, defined as a resection performed with curative intent according to the guidelines of the American Joint Committee on Cancer (AJCC) (6th and 7th edition), from stage IB to nonmetastatic IV disease [14]. Patients with a positive microscopic margin (R1 resection), with adequate function of the major organs (including cardiac, hepatic and renal functions) and bone marrow function (hemoglobin $>10 \mathrm{~g} / \mathrm{dl}$; leukocyte count $\geq 4000 / \mu \mathrm{l}$; platelet count $\geq 100000 / \mu \mathrm{l}$ ), and those who started treatment within 6 weeks following the surgery were included in the study. Patients who had a coexisting malignancy or those who could not tolerate chemotherapy due to systemic diseases were excluded from the study.

Patients were classified into two goups as those who could tolerate the adjuvant CRT treatment and those who could not. Intolerable group; patients suffering severe life-threatening toxicity as grade 3-4 hematologic (neutropenia and trombocytopenia) and gastrointestinal toxicity (severe mucositis, nausea, vomiting, abdominal pain, diarrhea etc) according to National Cancer Institute Common Toxicity Criteria. Because of these toxicities, dose reduction (generally in the ratio of 25\%) in chemotheraphy was applied and/or radiotheraphy was not entirely completed. The patients received generally at least half of radiotheraphy totally dose. This group of the patients was defined as those who could not tolerate the treatment and the remaining patients were defined as those who could tolerate the treatment. Patients of tolerable group entirely completed chemotheraphy and radiotheraphy.

Treatment and Follow-up of Patients. The ECOG (Eastern Cooperative Oncology Group) score of all patients was $\leq 2$ and they received the adjuvant CRT regimen developed by the North Central Cancer Treatment Group (INT0116) [15]. The chemotherapy protocol included a total of five treatment cycles with fluorouracil ( $425 \mathrm{mg} / \mathrm{m}^{2} /$ day, for 5 days) and leucovorin ( $20 \mathrm{mg} /$ $\mathrm{m}^{2} /$ day for 5 days). The radiotherapy consisted of $4500 \mathrm{cGy}$ of radiation at $180 \mathrm{cGy} /$ day; 5 days a week for 5 weeks.

Toxicity was graded as 1-4 based upon the National Cancer Institute Common Toxicity Criteria (version 2.0) [16]. The median follow-up period was 20.8 months (range: 1.5107 months). In the median follow-up period, 254 (35.1\%) patients died and 469 (64.9\%) still survive. Patients were monitored at three-monthly intervals for two years, followed by six-monthly intervals for three years, and at yearly visits thereafter. At the follow-up visits, patients underwent a physical examination, complete blood count and liverfunction tests, chest radiography and gastroduodenoscope and Computer Tomography scans as clinically indicated. The location and time point of the first relapse and the date of any deaths were recorded.

Statistical Analysis. RFS and OS were defined as the time from the date of the diagnosis to the date of the (histologically or radiologically) confirmed first relapse of cancer and the death of the patient, respectively. Data were analyzed using the SPSS 18 software package program. The Chi-square test was used for the comparison of the groups. Survival analyses were performed according to the Kaplan-Meier method with two-sided Log-rank statistics. Cox proportional hazards model analysis was carried out on the variables observed to be significant $(p<0.1)$ using the Log-rank test. These variables were found as the patients' age ( $<65$ years vs $>65$ years), sex, tumor localiza- 
tion, Lauren classification, grade, stage, type of the dissection, toxicity and tolerability status. P-values $<0.05$ were considered as significant.

\section{Results}

Patient Characteristics. The patient group consisted of 496 (68.6\%) males and 227 (31.4\%) females (median age 57 years; range: $21-85$ years). A total of 723 patients were registered for the adjuvant CRT treatment. The initial symptoms at the diagnosis included weight loss in 442 (61.2\%) patients; abdominal pain in $356(49.3 \%)$ patients, and anemia in 457 (63.3\%) patients. Among patients with anemia, 109 (23.8\%) had hemoglobin concentrations $<10 \mathrm{~g} / \mathrm{dl}$. The ECOG performance score of the patients was 2 in $67 \%$ and $0-1$ in $33 \%$. No statistically significant difference in terms of the performance score was observed between the groups that could and could not tolerate the treatment $(p=0.22)$. According to the AJCC staging system of patients $(n=723), 189(26.1 \%)$ were at stage IB-II, while $534(73.9 \%)$ were at stage III- IVM0. In 619 (85.5\%) of patients, the lymph nodes were positive; while the lymph nodes were negative in $105(14.5 \%)$ patients. According to the Lauren classification, $441(61.0 \%)$ patients had the intestinal type of gastric cancer and $282(39.0 \%)$ had the diffuse type. The intestinal type was more common among males (68.3\%) than females $(31.7 \%)$. Also, the diffuse type was more frequently observed among the male patients $(67.2 \%)(p=0.7)$. In our study, the median age was 57 years. In terms of the age, the intestinal type was observed to be more common among older patients (age $>57,53 \%$ ), while the diffuse type occurred more frequently in younger patients (age $<57,55.2 \%)(p=0.06)$. According to the localization of the tumor, $274(51.1 \%)$ of the patients $(n=536)$ had the distal type, while 262 (48.9\%) patients had the proximal type. In the examining of 98 patients in term of Helicobacter pylori (H. pylori) infection, $56(57.1 \%)$ of patients were positive $(p=0.8)$. Among the patients who were positive in terms of $\mathrm{H}$. pylori infection, 35 $(63 \%)$ had the intestinal type of gastric cancer, while $21(37 \%)$ had the diffuse type $(p=0.6)$. Moreover $55.8 \%$ of the distal type of gastric cancer patients were positive for H. pylori $(p=0.3)$.

Patients who underwent subtotal gastrectomy comprised $50.5 \%$ of the total patient group. Regarding the lymph node status of the patients, $618(85.5 \%)$ had nodal metastases while $105(14.5 \%)$ patients were confirmed to be node-negative based on the surgical specimen. Patients were classified as either high (grade 3) or low-middle (grades 1 and 2). Among the patients, $345(47.8 \%)$ had grade 3 disease. Patient characteristics are

Table 1. Univariate analysis of variables with influence on survival and relapse

\begin{tabular}{|c|c|c|c|c|c|}
\hline \multirow[t]{2}{*}{ Characteristics } & \multirow[t]{2}{*}{$n(\%)$} & \multirow{2}{*}{\multicolumn{2}{|c|}{$\begin{array}{c}\text { RFS } \\
\text { value }\end{array}$}} & \multicolumn{2}{|l|}{ OS } \\
\hline & & & & Months & $p$ value \\
\hline \multicolumn{6}{|l|}{ Age Group } \\
\hline $65<$ & $560(77.5)$ & 24.4 & 0.16 & 48.4 & 0.003 \\
\hline $65>$ & $163(22.5)$ & 19.0 & & 27.0 & \\
\hline \multicolumn{6}{|l|}{ Sex } \\
\hline Female & $496(68.6)$ & 42.1 & 0.819 & 63.7 & 0.09 \\
\hline Male & $227(31.4)$ & 35.3 & & 52.5 & \\
\hline \multicolumn{6}{|l|}{ Localization } \\
\hline Proximal & $354(48.9)$ & 31.3 & 0.02 & 34.6 & 0.04 \\
\hline Distal & $369(51.1)$ & 62.7 & & 56.5 & \\
\hline \multicolumn{6}{|l|}{ Lauren class. } \\
\hline Intestinal & $441(61.0)$ & 42.5 & 0.004 & 52.0 & $<0.001$ \\
\hline Diffuse & $282(39.0)$ & 26.1 & & 25.8 & \\
\hline \multicolumn{6}{|l|}{ Grade } \\
\hline Low-Middle & $378(52.2)$ & 42.5 & 0.06 & 55.0 & 0.003 \\
\hline High & $345(47.8)$ & 31.3 & & 32.2 & \\
\hline \multicolumn{6}{|l|}{ Stage } \\
\hline $\begin{array}{l}\text { Ib } \\
\text { II }\end{array}$ & $\begin{array}{c}48(6.6) \\
141(19.5)\end{array}$ & * & & * & \\
\hline IIIa & $301(41.6)$ & 30.5 & $<0.001$ & 34.0 & $<0.001$ \\
\hline IIIb & $143(19.8)$ & 19.0 & & 23.8 & \\
\hline IV(M0) & $90(12.4)$ & 18.5 & & 23.5 & \\
\hline \multicolumn{6}{|l|}{ Dissection } \\
\hline D1 & $257(35.5)$ & 34.6 & 0.445 & 32.7 & 0.043 \\
\hline D2 & $468(64.5)$ & 38.1 & & 48.4 & \\
\hline \multicolumn{6}{|l|}{ Toxicity $^{* *}$} \\
\hline Yes & $193(26.7)$ & 31.2 & 0.062 & 38.1 & 0.077 \\
\hline No & $530(73.3)$ & 40.0 & & 46.1 & \\
\hline \multicolumn{6}{|l|}{ Tolerability } \\
\hline Yes & $626(86.6)$ & 40.0 & 0.002 & 48.0 & 0.001 \\
\hline No & $97(13.4)$ & 20.5 & & 27.0 & \\
\hline Total & $723(100)$ & & & & \\
\hline
\end{tabular}

${ }^{\star}$ Median Overall Survival has not been reached. ${ }^{\star \star}$ Grade $3-4$ Hematologic and non hematologic toxicity. ${ }^{\star \star \star}$ Tolerability to adjuvant therapy 


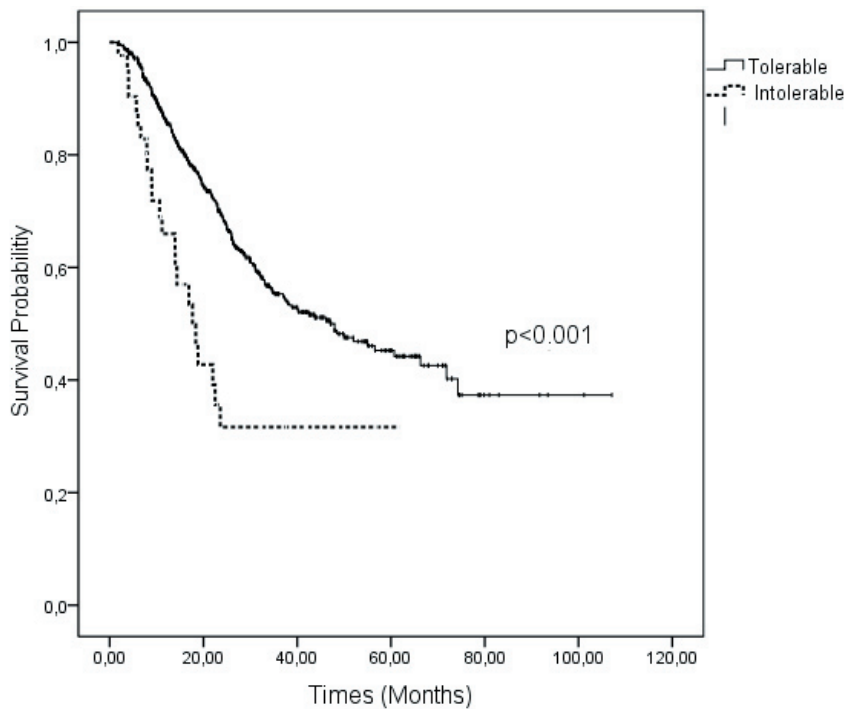

Figure 1. Kaplan-Meier Curve of Overall Survival for tolerability.

summarized in Table 1 and 2. The tumor grade according to the Lauren classification revealed that 297 (67.3\%) patients in the intestinal group had low-grade tumors, while $220(78 \%)$ in the diffuse group had high grade tumors $(\mathrm{p}<0.001)$. No statistically significant relationship was observed between the tumor localization and the patients' sex, Lauren classification and $\mathrm{H}$. pylori status. In addition, no statistically significant relationship was found between the tumor localization and tumor grade $(\mathrm{p}=0.6)$, disease stage $(\mathrm{p}=0.1)$, and surgical dissection $(\mathrm{p}=0.4)$.

Table 2. Characteristics of Intolerable and Tolerable Patients

\begin{tabular}{lccc}
\hline & Intolerable & Tolerable & \\
\hline Characteristics & $n(\%)$ & $n(\%)$ & $p$ value \\
\hline Age & & & \\
$\quad<65$ & $72(74.2)$ & $487(77.8)$ & 0.43 \\
$\quad>65$ & $25(25.8)$ & $139(22.2)$ & \\
Sex & & & \\
$\quad$ Male & $66(68.0)$ & $196(31.3)$ & 0.89 \\
$\quad$ Female & $31(32.0)$ & $430(68.7)$ & \\
Grade & & & \\
$\quad$ Low & $57(58.7)$ & $321(51.3)$ & 0.27 \\
$\quad$ High & $40(41.3)$ & $305(48.7)$ & \\
Stage & & & \\
$\quad$ I-II & $19(19.6)$ & $170(27.2)$ & 0.08 \\
$\quad$ III-IVM0 & $78(80.4)$ & $456(72.8)$ & \\
Lauren & & & \\
$\quad$ Intestinal & $66(68.0)$ & $375(60.0)$ & 0.18 \\
$\quad$ Diffuse & $31(32.0)$ & $251(40.0)$ & \\
Localization & & & \\
$\quad$ Proximal & $46(47.4)$ & $308(49.2)$ & 0.67 \\
$\quad$ Distal & $51(52.6)$ & $318(50.8)$ & \\
Dissection & & & \\
D1 & $38(39.2)$ & $227(36.2)$ & 0.59 \\
D2 & $59(60.8)$ & $399(63.8)$ & \\
\hline
\end{tabular}

There was no statisticallysignificant relationship between the type of surgery and the pathological type either $(p=0.9)$.

Treatment Results. Curative surgery was performed in 723 patients. While 661 (91.4\%) patients had clear surgical margins (R0 resection), 62 (8.6\%) patients had microscopic surgical margin involvement (R1 resection). D2 lymph node dissection was carried out in 444 (61.4\%) of the patients. The median number of the lymph nodes dissected and involved were 18 (range: $0-60$ ) and 4 (range: 0-48), respectively.

Adjuvant chemo-radiotheraphy treatment according to the INT 0016 study was started in the patients at stage IB to IV (M0). Generally, grade 1-4 hematologic and non-hematologic (gastrointestinal and renal) toxicities were observed at a rate of $46 \%(n=332)$. Grade 3-4 toxicity (hematologic and gastrointestinal) occurred at a rate of $26.7 \%(n=193)$. The most common severe gastrointestinal toxicities were nausea, vomiting and diarrhea. The treatment was intolerable in 97 patients (13.4\%) and couldn't have been completed the entire chemoradiotherapy protocol because of toxicity. Chemotheraphy dose reduction was applied for 53 patients $(7.3 \%)$ and $44(6 \%)$ patients did not complete the entire radiotheraphy.

Survival Results. The survival analysis was based on 723 patients. The median follow-up period was 20.8 months (range: 1.5-107 months). In the Kaplan-Meier analysis, the median OS and RFS were found as 43.7 and 36.6 months, respectively (with censored variables). The OS rates were $80 \%$, $52 \%$, and $38 \%$; while the RFS rates were $75 \%, 48 \%$, and $34 \%$ at 1,3 and 5-years, respectively. In the median follow-up period, relapse was observed in 279 patients (41.7\%) and 254 (35.1\%) among them died. Univariate analysis of variables with influence on survival and relapse are summarized in Table- 1 .

The survival analysis indicated that the overall survival of patients $\geq 65$ years of age was 27.0 months, while the overall survival of patients $<65$ years was 48.4 months $(p=0.003)$. The RFS for patients $\geq 65$ years was 19.0 months, while this duration was 24.4 months in patients $<65$ years of age $(p=0.10)$.

In patients with an ECOG performance score of 2, the survival rate was lower than the patients with a score of $0-1$ (for RFS $\mathrm{p}=0.3$, OS $\mathrm{p}=0.01$ ). No significant difference was found between the sex and the OS $(\mathrm{P}=0.09)$; and between the sex and the RFS rate $(p=0.8)$. There was no significant difference between anemia, weight loss, or OS ( $\mathrm{p}=0.2, \mathrm{p}=0.1)$. No significant difference was observed between the anemia, weight loss and RFS rates either $(\mathrm{p}=0.8, \mathrm{p}=0.5)$.

In patients with toxicity, the OS and RFS rates were worse than in patients with no toxicity observed $(\mathrm{p}=0.077, \mathrm{p}=0.062)$. Patients who could not tolerate the therapy had statistically significantly lower OS and RFS rates compared to the other patients ( $\mathrm{p}=0.001, \mathrm{p}=0.002$ respectively). The Kaplan-Meier Curve of Overall Survival demonstrates a significant difference between the groups that could and could not tolerate the treatment, Figure-1. Kaplan-Meier Curve of Overall Survival shows significant difference between stage I- IVM0 groups in Figure-2. Five year survival rates of stage I, II, IIIA, IIIB and IV(M0) patients were 85.5\%, 69.6\%, 34.7\%, 
$32.9 \%$ and $34.6 \%$, respectively. RFS rates were $92.3 \%-80.3 \%$, $94.4 \%-76.1 \%, 84.3 \%-45.8,66.6 \%-36.1 \%$ and $59.5 \%-30.2 \%$, at 1-3 years for stage I, II, IIIA, IIIB, IV respectively. The relationship between the overall stage and survival is well defined in Table-1.

In the Log-rank test of the subgroups, the Lauren classification, localization of the tumor, tumor grade, type of the operation and type of dissection were observed to be significantly different in terms of both the OS and RFS. In the evaluation of the analysis, results with values of $\mathrm{p}<0.1$ were analyzed through the cox regression analysis. Also in the cox regression analysis, tumor stage (HR: 0.332; 95\% confidence interval (CI): 0.195-0.566; $\mathrm{p}<0.001)$, and tolerability (HR: 0.516; 95\% CI: 0.305-0.872; $\mathrm{p}=0.014$ ), were found to be related to the OS. In the cox regression analysis, tumor stage (HR: 0.318; 95\% CI: 0.190-0.533; $\mathrm{p}=<0.001$ ) and tolerability (HR: $0.604 ; 95 \%$ CI: $0.367-0.995 ; \mathrm{p}=0.048$ ) were observed to be statistically significant in terms of the RFS. OS and RFS survival analysis results are summarized in Table-3.

\section{Discussion}

The incidence and mortality rates of gastric cancer vary widely in different regions of the world [8]. In Turkey, the incidence of gastric cancer is between the higher incidence in the Eastern world (Japan, Southeast Asia) and the lower incidence in the West (United States) [2]. Epidemiological studies have shown a decrease in the gastric cancer incidence in Turkey in the last decades [3].

Gastric cancer generally occurs more frequently in males, and the male-to-female ratio is about 1.5/1 [17]. According to the studies conducted in Turkey, the male to female ratio is $1.5 / 2$ and the mean age of the patients is 57 years [18]. Among these patients, $71.2 \%$ had stage 3 and 4 disease [19]. Our results pointed out the male to female ratio as $2 / 1$ and the median age as 57 years. Also, $73.8 \%$ of patients were in the locally advanced stage. One of the reasons the patients

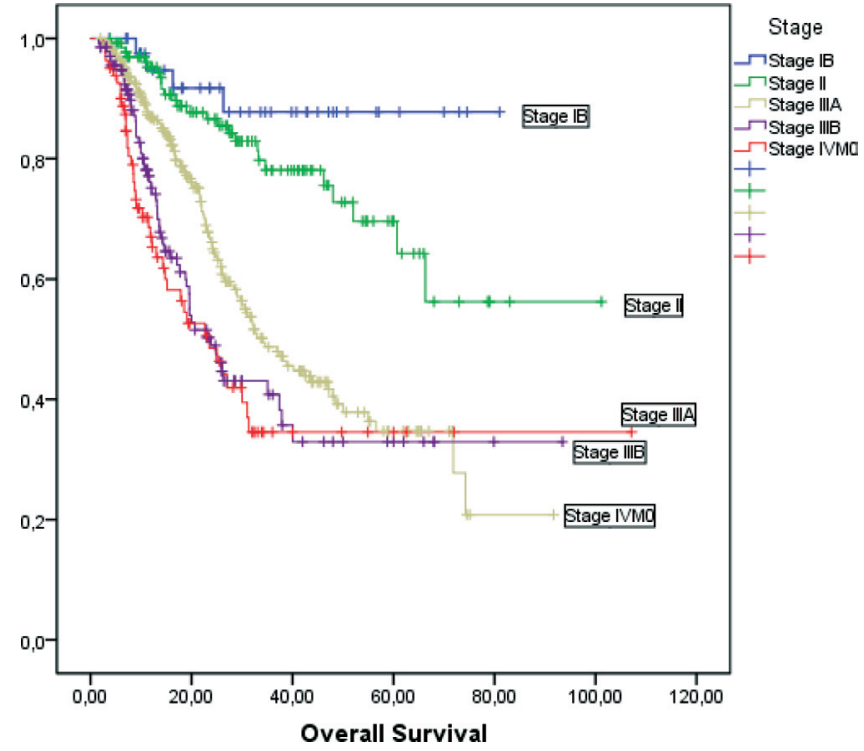

Figure 2. Kaplan-Meier Curve of Overall Survival for tumor stage.

are diagnosed in an advanced stage is that no gastric cancer screening programs are in application in Turkey.

In our study, the frequencies of proximal and distal tumor localizations were found to be comparable. According to the Lauren classification, $61.0 \%$ of the patients had the intestinal type of gastric cancer. Globally, the intestinal type of the tumor is more commonly observed both in general, and in males and the elderly. In a large study conducted in Turkey, two-thirds of the patients were found to be in the advanced stage; and both the distally located tumors, and the intestinal type of gastric cancer were more frequently observed [19]. In contrast to the increasing incidence of proximal tumors in the western world, distal tumors continue to predominate in Japan [9].

The localization of gastric cancer has changed from distal to more proximal in recent years and this is also the case for our

Table 3. Multivariate analysis of variables with influence on survival and relapse

\begin{tabular}{|c|c|c|c|c|}
\hline \multirow[t]{2}{*}{ Characteristic } & \multicolumn{2}{|c|}{ On relapse } & \multicolumn{2}{|c|}{ On survival } \\
\hline & Hazard Ratio $(95 \% \mathrm{CI})$ & $\mathrm{p}$ value & Hazard Ratio $(95 \% \mathrm{CI})$ & $\mathrm{p}$ value \\
\hline Lauren Classification (diffuse or Intestinal) & $0.681(0.446-1.038)$ & 0.074 & $0.699(0.450-1.085)$ & 0.110 \\
\hline Stage(IVM0-IB) & $0.318(0.190-0.533)$ & $<0.001$ & $0.332(0.195-0.566)$ & $<0.001$ \\
\hline Tolerability(No or Yes) & $0.604(0.367-0.995)$ & 0.048 & $0.516(0.305-0.872)$ & 0.014 \\
\hline Toxicitiy (No or Yes) & $0.975(0.648-1.468)$ & 0.904 & $0.933(0.605-1.438)$ & 0.752 \\
\hline $\begin{array}{l}\text { Localization } \\
\text { (Proximal or Distal) }\end{array}$ & $1.262(0.894-1.782)$ & 0.186 & $1.296(0.906-1.853)$ & 0.156 \\
\hline $\begin{array}{l}\text { Dissection } \\
\text { (D1 or D2) }\end{array}$ & $0.859(0.584-1.265)$ & 0.442 & $1.107(0.756-1.622)$ & 0.600 \\
\hline $\begin{array}{l}\text { Grade } \\
\text { (High or Low/Middle) }\end{array}$ & $0.937(0.624-1.407)$ & 0.753 & $0.734(0.477-1.128)$ & 0.158 \\
\hline $\begin{array}{l}\text { Age } \\
(>65 \text { or }<65)\end{array}$ & $0.911(0.606-1.369)$ & 0.653 & $0.848(0.558-1.287)$ & 0.438 \\
\hline
\end{tabular}


country but distal domination was prominent ten years ago [20]. Generally, proximal carcinomas have a poorer prognosis than distal cancers. In our study, the patients who had tumors with higher histological grades had a poor prognosis. The risk of non-cardia gastric cancer was about six times higher in those who were tested positive for $\mathrm{H}$. pylori. $\mathrm{H}$. pylori infection was detected more frequently in the intestinal type of tumor than in distal gastric cancer. In the study conducted on a Turkish population, positive $\mathrm{H}$. Pylori tests were more common in patients with distal gastric cancer and intestinal type of tumor; and the difference was found as statistically significant [21].

Our study also revealed that the ratio of the patients who underwent subtotal or total gastrectomies were similar. Patients who had subtotal gastrectomies had better survival rates. This may be due to the advantage these patients had in terms of the quality of life, lower morbidity rates, lower number of postoperative complication and the generally good prognosis of the distal tumors. In our study, more than half (61.4\%) of the patients had undergone D2 nodal surgery. Patients who had undergone D2 nodal dissections had better RFS and OS rates in the univariate and multivariate analyses compared to the patients who had D1 dissections. In western countries, extended lymph node dissection in resectable gastric cancer has not been demonstrated to increase the survival significantly [22]. Thus, extended lymph node dissection is still a controversial issue in the West, while D2 dissection during gastrectomy is the standard procedure in Japan. Currently, there is no universally accepted adjuvant treatment regimen for gastric cancer. In our country, the generally accepted treatment modality is the INT006 study treatment for gastric cancer. When our study and the INT006 study were compared, the OS rates for 3 years were $52 \%$ and $50 \%$, respectively. Also, the RFS rates were $48 \%$ and $48 \%$, respectively. Although the survival rates in our study were similar to Europe and America, they were lower than certain countries like Japan. The 5-year survival rate in Japan is over $50 \%$ [23]. These higher survival rates in gastric cancer in Japan in comparison to the western countries are related to the different histopathological and biological characteristics of gastric cancer and the screening programs in effect.

The disadvantage of adjuvant CRT as a standard treatment for gastric cancer is its significant toxicity. Due to this disadvantage, $17 \%$ of patients terminated the treatment because of the toxic effects in the INT-0116 study, while in our study, this ratio was $13.4 \%(\mathrm{n}=97)$. According to our clinical observations, patients who terminated the adjuvant CRT early as a result of intolerance had a worse prognosis and lower survival rates. In our opinion, modifying the treatment protocol of the patients who cannot tolerate adjuvant CRT to contain less toxic, but effective adjuvant therapies such as oral fluoropyrimidine, capecitabine and platin treatments may be beneficial $[24,25]$.

Consequently, Turkey is in the middle of the transit roads between Asia and Europe, the Turkish patient population cannot be classified under the Eastern or the Western type of gastric cancer patients and may show different features from either of the types. In the multivariate analyses, the Lauren classification, tumor stage and tolerability were observed to be statistically significant in terms of the OS and RFS, and these were defined as marked prognostic factors. We are of the opinion that the treatment of the patients who cannot tolerate adjuvant CRT should be replaced with less toxic adjuvant therapies.

\section{References}

[1] PARKIN DM, BRAY F, FERLAY J, PISANI P. Global cancer statistics, 2002. CA Cancer J Clin 2005; 55(2): 74-108. http:// dx.doi.org/10.3322/canjclin.55.2.74

[2] SUAYIB YALCIN. Gastric Cancer in Turkey-A Bridge Between West and East. Gastrointest Cancer Res 2009; 3(1): 29-32.

[3] FIDANER C, ESER SY, PARKIN DM. Incidence in Izmir in 1993-1994: first results from Izmir Cancer Registry. Eur J Cancer 2001; 37(1): 83-92. http://dx.doi.org/10.1016/S09598049(00)00355-5

[4] OHNO Y, NAKAMURA T, MURATA K, TSUKUMA H, AJIKI W, et al. Prediction of the future incidence of cancer in Japan. In: Oshima A, Kuroishi T, Tajima K (eds). White Paper on Cancer and Statistics- Incidence/Mortality/Prognosis-2004. Shinohara-shuppan, Tokyo, 2004; 201-17.

[5] KAMANGAR F, DORES GM, ANDERSON WF. Patterns of cancer incidence, mortality, and prevalence across five continents: defining priorities to reduce cancer disparities in different geographic regions of the world. J Clin Oncol 2006; 24: 2137-50. http://dx.doi.org/10.1200/JCO.2005.05.2308

[6] CUNNINGHAM D, CHUA Y. J. East meets west in the treatment of gastric cancer. New England Journal of Medicine.2007; 357 (18): 1863-65. http://dx.doi.org/10.1056/ NEJMe078182

[7] AKOH JA, MACINTYRE IM. Improving survival in gastric cancer: review of 5-year survival rates in English language publications from 1970. Br J Surg 1992; 79: 293-9. http:// dx.doi.org/10.1002/bjs.1800790404

[8] ITZHAK AVITAL, PETER W. T. PISTERS, DAVID P. KELSEN, CHRISTOPHER G.WILLETT. Cancer of the stomach. In Devita VT, Lawrence T, and Rosenberg SA (eds): Cancer: Principles and Practise of Oncology. 9th edition. Philadelphia Lippincott Williams \&Wilkins; 2011: 924-954.

[9] CATALANO V, LABIANCA R, BERETTA GD, GATTA G, DE BRAUD F, et al. Gastric Cancer. Crit Rev Oncol Hematol 2009; 71(2): 127-64. http://dx.doi.org/10.1016/ j.critrevonc.2009.01.004

[10] LAUREN P. The two histological main types of gastric carcinoma: diffused and so-called intestinal-type carcinoma. An attempt at a histo-clinical classification. Acta Pathol Microbiol Scand 1965; 64: 31-49.

[11] LIU Y, KANEKO S, SOBUE T. Trends in reported incidences of gastric cancer by tumour location, from 1975 to 1989 in Japan. Int J Epidemiol 2004; 33: 808-15. http://dx.doi. org/10.1093/ije/dyh053 
[12] VAN KRIEKEN JH, SASAKO M, VAN DE VELDE CJ. Gastric cancer. In: Gospodarowicz MK, Henson DE, Hutter RVP, O'Sullivan B, Sobin LH, Wittekind C (eds): Prognostic factors in cancer. New York: Wiley-Liss; 2001: 251-65.

[13] BALDUCCI L, EXTERMANN M. Management of cancer in the older person: a practical approach. Oncologist 2000; 5: 224-237. http://dx.doi.org/10.1634/theoncologist.5-3-224

[14] STEPHEN B. EDGE, CAROLYN C. COMPTON, The American Joint Committee on Cancer: the 7th Edition of the AJCC Cancer Staging Manual and the Future of TNM. Ann Surg Oncol 2010; 17(6): 1471-4.

[15] MACDONALD JS, SMALLEY SR, BENEDETTI J, HUNDAHL SA, ESTES NC et al. CRT after surgery compared with surgery alone for adenocarcinoma of the stomach or gastroesophageal junction. N Engl J Med 2001; 345: 725-30. http://dx.doi.org/10.1056/NEJMoa010187

[16] AJANI JA, WELCH SR, RABER MN, FIELDS WS, KRAKOFF IH. Comprehensive criteria for assessing therapy-induced toxicity. Cancer Invest 1990; 8: 147-59.

[17] J. FERLAY, F. BRAY, P. PISANI, D.M. PARKIN. GLOBOCAN 2002 cancer incidence, mortality and prevalence worldwide. IARC cancerBase No. 5, version 2.0, Lyon: IARC Press 2004.

[18] YALCIN B, ZENGIN N, AYDIN F, ILHAN M, ISIKDOGAN A, et al. The clinical and pathological features of patients with gastric cancer in Turkey: A Turkish Oncology Group study. Turk J Cancer 2006; 36: 108-115.

[19] G. DEMIR, E. BUYUKUNAL, E. KIZILKILIC, M. OZGUROGLU, N. MANDEL, et al. Gastric cancer in Turkey: a single center experience of 683 cases. J Clin Oncol 2004; 22(suppl 14) (abstr 4254).
DURSUN M, YILMAZ S, CANORUC F, ISIKDOGAN A, KILINC N, et al. Anatomic Localization in Gastric Carcinoma. Journal of Dicle Medical School.2002; 29: 1-2.

[21] SERHAT BOR, RUKIYE VARDAR, NECATI ORMECI, FARUK MEMIK, INCI SULEYMANLAR. Prevalence patterns of gastric cancers in Turkey: Model of a developing country with high occurrence of Helicobacter pylori. Journal of Gastroenterology and Hepatology 2007; 22 (12): 2242-45. http://dx.doi.org/10.1111/j.1440-1746.2006.04737.x

[22] HARTGRINK HH, VAN DE VELDE CJ, PUTTER H, BONENKAMP JJ, KLEIN KRANENBARG E, et al. Extended lymph node dissection for gastric cancer: who may benefit? Final results of the randomized Dutch gastric cancer group trial. J Clin Oncol 2004; 22(11): 2069-77. http://dx.doi. org/10.1200/JCO.2004.08.026

[23] NAOMI SATO, YURI ITO, AKIKO IOKA, MASAHIRO TANAKA, HIDEAKI TSUKUMA. Gender Differences in Stomach Cancer Survival in Osaka, Japan: Analyses Using Relative Survival Model. Jpn J Clin Oncol 2009; 39(10): 690-94. http://dx.doi.org/10.1093/ijco/hyp084

[24] SAKURAMOTO S, SASAKO M, YAMAGUCHI T, KINOSHITA T, FUJII M, et al. ACTS-GC Group. Adjuvant chemotherapy for gastric cancer with $\mathrm{S}-1$, an oral fluoropyrimidine. N Engl J Med. 2007; 357(18): 1810-20. http://dx.doi. org/10.1056/NEJMoa072252

[25] BANG YJ, KIM YW, YANG HK, CHUNG HC, PARK YK, et al. CLASSIC trial investigators. Adjuvant capecitabine and oxaliplatin for gastric cancer after D2 gastrectomy (CLASSIC): a phase 3 open-label, randomised controlled trial. Lancet. 2012; 28(379): 315-21. 